\title{
Uterine volume measurement as a determinant in route of hysterectomy
}

\author{
Dudekula Hanifa*, Nandita A. Thakkar, R. Premalatha
}

Department of Obstetrics and Gynecology, Mehta Multispeciality Hospitals, Chennai, Tamil Nadu, India

Received: 12 September 2021

Accepted: 11 October 2021

\author{
*Correspondence: \\ Dr. Dudekula Hanifa, \\ E-mail: hanisweety4@gmail.com
}

Copyright: (C) the author(s), publisher and licensee Medip Academy. This is an open-access article distributed under the terms of the Creative Commons Attribution Non-Commercial License, which permits unrestricted non-commercial use, distribution, and reproduction in any medium, provided the original work is properly cited.

\begin{abstract}
Background: Objectives of the study were to determine the role of uterine volume rather than uterine length in assessing the route of hysterectomy; to estimate the cut-off of uterine volume for route of hysterectomy; and to correlate uterine volume measured preoperatively by ultrasound with post-operative uterine weight.

Methods: This was a prospective observational study including a total of 101 women who underwent hysterectomies (vaginal, laparascopic assisted vaginal hysterectomy (LAVH), total laparascopic hysterectomy (TLH), abdominal) in a period of 2 years 2 months from July 2018 to August 2020 in Mehta Multispeciality Hospital, Chetpet, Chennai. Uterine size was measured by clinical examination. Ease of the procedure with various uterine volume and routes of hysterectomy were studied.

Results: 51 (50.49\%) underwent vaginal route (including laparascopic hysterectomy), 50 (49.50\%) underwent abdominal hysterectomy. Mean uterine volume leading to removal vaginally was $168.09 \pm 139.28 \mathrm{cc}$ whereas $309.12 \pm 182.47 \mathrm{cc}$ for abdominal hysterectomy $(\mathrm{p}=0.001)$ which was statistically significant. vaginal hysterectomy was done without difficulty up to $300 \mathrm{cc}$. Postoperative complications were less with vaginal hysterectomy compared to abdominal hysterectomy was statistically significant $(\mathrm{p}=0.0001)$.Uterine volume measured pre operatively by ultrasound showed positive correlation $(\mathrm{r}=0.82)$ with post-operative uterine weight proved that uterine volume measurements was superior to the clinical estimate of uterine size in assessing the route of hysterectomy.

Conclusions: Uterine volume on ultrasonography (USG) can be a good predictor in deciding whether hysterectomy via vaginal route is possible.
\end{abstract}

Keywords: Vaginal hysterectomy, Abdominal hysterectomy, Uterine volume

\section{INTRODUCTION}

Hysterectomy is the most commonly performed gynaecological surgical procedure. Of the various surgical approaches used to remove the uterus, the majority are still approached abdominally (64\%); while vaginal (22\%), and laparoscopic (14\%) hysterectomies continue to gain popularity. However, the prevalence of hysterectomy appears to be decreasing, possibly due to the advent of less invasive therapies for management of conditions previously treated with hysterectomy.

The choice of surgical approach depends upon the indications for the procedure, concomitant procedures, and surgical outcomes of each approach, surgeon experience, and patient preference. In general, a surgeon should choose the procedure which maximizes patient safety and the best for achieving the goal of the surgery. ${ }^{1}$

Vaginal hysterectomy is indicated in women with mobile uteri no larger than 12 weeks gestational size ( 280 g), suggesting that uteri greater than $280 \mathrm{~g}$ are appropriately performed by the abdominal route. Coring, bivalving and morcellation are well accepted methods of reducing an enlarged uterus so that it can be removed transvaginally. Incorporated uterine size, mobility, accessibility and pathology confined to the uterus are selection criteria for vaginal hysterectomy. ${ }^{2}$ 


\section{Uterus volume to weight conversion}

Linear regression analysis was revealed.

Uterine weight $(g)=50.0+0.71 \times$ volume $\left(\mathrm{cm}^{3}\right)$

Here, correlation coefficient is 0.93 and SE is $49.6 \mathrm{~g}$.

There was a close, positive correlation between the estimated uterine volume and actual uterine weight. Uterine volume includes three dimensions of uterus whereas uterine size (in weeks) is based only on fundal height. Three uteri with same fundal height but different volumes, because of different AP diameter and breadth. ${ }^{3,4}$ Hence uterine volume is one of the deciding factor for the route of hysterectomy.

Vaginal and laparoscopic procedures are considered "minimally invasive" surgical approaches because they do not require a large abdominal incision and, thus, typically are associated with shortened hospitalization and postoperative recovery times compared with open abdominal hysterectomy. Minimally invasive approaches to hysterectomy should be performed, whenever feasible, based on their well-documented advantages over abdominal hysterectomy. The vaginal approach is preferred among the minimally invasive approaches. Laparoscopic hysterectomy is a preferable alternative to open abdominal hysterectomy for those patients in whom a vaginal hysterectomy is not indicated or feasible. ${ }^{5}$

Vaginal hysterectomy is least expensive, least invasive, least morbidity and with most rapid post-operative recovery. Operative time and duration of hospital stay are usually shortest for vaginal hysterectomy. Intraoperative and postoperative complications are more for abdominal hysterectomy. Early ambulation and early regular diet is possible with vaginal hysterectomy. ${ }^{6}$

\section{Aim}

Aims and objectives were: to determine the role of uterine volume rather than uterine length in assessing the techniques of hysterectomy; to estimate the cut-off of uterine volume for route of hysterectomy; and to correlate uterine volume measured preoperatively by ultrasound with postoperative uterine weight.

\section{METHODS}

A prospective observational study done at Mehta Multispecialty Hospitals, Chennai from July 2018 August 2020. Pre-operative ultrasound done for 101 patients admitted in the gynaecology ward for various routes of hysterectomy was reviewed. Uterine size was measured by clinical examination. During surgery patients in whom specimen was removed abdominally (TAH) were grouped together and in whom specimen was removed vaginally [vaginal hysterectomy $(\mathrm{VH})$, laparascopic assisted vaginal hysterectomy (LAVH), total laparoscopic hysterectomy (TLH) (specimen removed vaginally/morcellation)] were grouped together. Intraoperatively cases which needed various methods of debulking were noted. Duration of surgery and intra operative complications of various routes of hysterectomy were noted. Weight of specimen was recorded and compared with preoperative ultrasound volume. Ease of the procedure with various uterine volume and routes of hysterectomy were studied.

\section{Inclusion criteria}

Indications will be benign disorders like AUB, fibroids, endometriosis, prolapsed uterus, post-menopausal bleeding.

\section{Exclusion criteria}

Factors like restricted uterine mobility, and gynaecologic cancer.

\section{Statistical analysis}

Data collected from the study subjects were entered in the master chart using Microsoft excel.

All the data was tabulated in different frequency tables and analyzed. The inferential statistics are done using student ' $t$ ' test for comparing means and Chi square test for comparing proportions. The cut off value will be determine using receiver operating characteristic (ROC) curve. Statistical significance was determined at the $5 \%$ level of significance $(\mathrm{p}<0.05)$.

\section{RESULTS}

Total number of patients included in the study was 101 .

Out of total 101 women, $51(50.49 \%)$ underwent vaginal route (including laparoscopic hysterectomy), out of which $21(20.79 \%)$ patients underwent vaginal, 20 (19.8\%) patients underwent LAVH, 10 (9.9\%) underwent TLH (specimen removed vaginally). $50(49.50 \%)$ underwent abdominal hysterectomy.

In this study, parous women had undergone more hysterectomy, 55 women $(54 \%)$ were para 2 , majority of women have no co morbidities 57 (56.4\%) (Table 1).

Among 101 patients who had underwent hysterectomy, when there was an increase in uterine size on clinical examination there was a corresponding increase in the mean uterine volume measured on ultrasound (Table 2).

It was found as the breadth of the uterus increases the chances of vaginal hysterectomy significantly decreased and was statistically significant $(\mathrm{p}=0.012)$ (Table 3$)$.

Among 101 patients who had undergone hysterectomy, whenever there was an increase in pre-operative uterine 
volume by ultrasonography (USG), it was associated with a corresponding increase in uterine weight measured post operatively, showing positive a correlation between uterine weight measured postoperatively and pre-operative uterine volume (Figure 1).

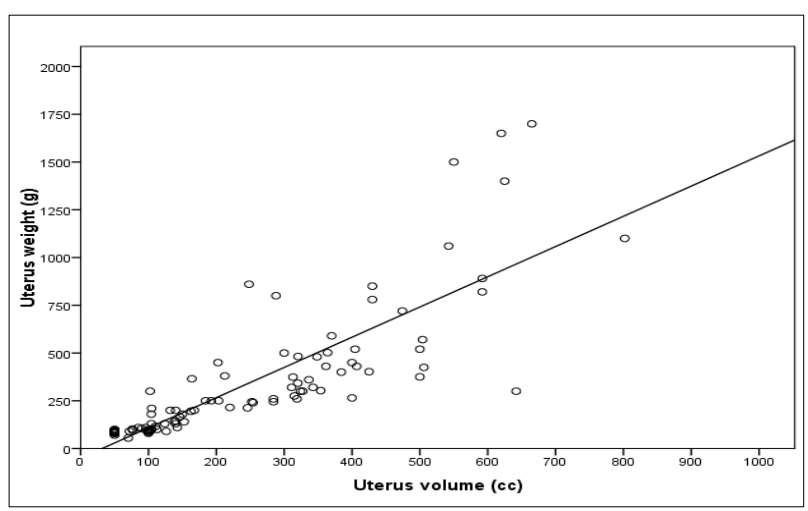

Figure 1: Comparison of uterine volume (cc) and uterine weight (grams).

Correlation coefficient, $\mathrm{r}=0.823$; $\mathrm{p}$ value $=0.001$ *

There is a positive correlation between all three parameters - uterine weeks, pre-operative uterine volume and postoperative uterine weight. However, the area under the curve is the greatest for uterine volume indicating that it can be the best predictor in deciding the route of hysterectomy (Figure 2). Uterine volume more than $286 \mathrm{cc}$ indicates that the probability of undergoing an abdominal hysterectomy is high.

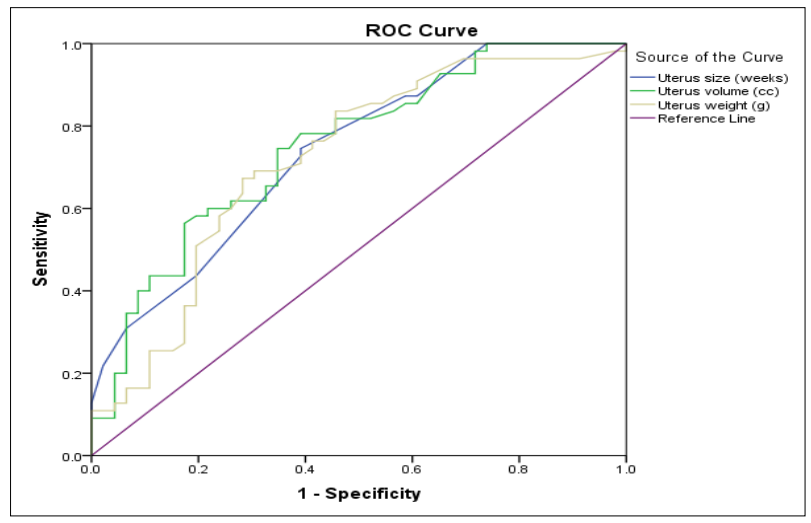

Figure 2: ROC curve - comparison of uterine size, uterine volume and uterine weight.

Abdominal hysterectomy was done with significantly higher mean uterine size of $13.76 \pm 4.53$ weeks compared to vaginal hysterectomy with uterine size of $8.46 \pm 5.54$ weeks only $(\mathrm{p}=0.001)$. Mean uterine volume leading to removal vaginally was $168.09 \pm 139.28 \mathrm{cc}$ whereas $309.12 \pm 182.47 \mathrm{cc}$ for abdominal hysterectomy $(\mathrm{p}=0.001)$ (Table 4).

Vaginal route is the maximum when the uterine volume ranges from 100-200 cc. Abdominal route was done when uterine volume is $>500 \mathrm{cc}$. Among those with uterine volume of 300-500 cc a choice of laparoscopically assisted vaginal route or vaginal route with debulking were the options depending upon the patients' preference, operating centre and surgical expertise available in the centre. It was observed that with an increasing uterine volume there was a corresponding increase in the operative time (Table 5).

In this study mean operative time of abdominal route is $65.2 \mathrm{~min}$ whereas mean operative time of vaginal route is 54.4 min. Mean operative time in vaginal route is significantly less compared to abdominal route $(\mathrm{p}=0.001)$.

Mean hospital stay of abdominal route is 3.38 days whereas mean hospital stay of vaginal route is 2.50 days. Mean hospital stay in vaginal route is significantly less compared to abdominal route $(\mathrm{p}=0.001)$.

Table 1: Demographic features of total hysterectomies.

\begin{tabular}{|ll|}
\hline Baseline characteristics & Value $(\%)$ \\
\hline Mean age (in years) & $47.55( \pm 7.87)$ \\
\hline Parity & \\
\hline Para-1 & $33(32.6)$ \\
\hline Para-2 & $55(54)$ \\
\hline Para-3 & $6(5.9)$ \\
\hline Para-4 & $6(5.9)$ \\
\hline Co morbidities & $6(5.9)$ \\
\hline DM & $21(20.7)$ \\
\hline Hypertension & $8(7.9)$ \\
\hline HTN+DM & $8(7.9)$ \\
\hline Endometriosis & $1(0.99)$ \\
\hline CA thyroid & $57(56.4)$ \\
\hline Nil & \\
\hline Previous surgeries & $16(15.8)$ \\
\hline 1 caesarean section & $2(1.98)$ \\
\hline 1 caesarean section + myomectomy & $1(0.99)$ \\
\hline $\begin{array}{l}\text { 1 + caesarean section ovarian } \\
\text { cystectomy }\end{array}$ & $15(14.8)$ \\
\hline 2 caesarean sections & $2(1.98)$ \\
\hline 2 caesarean section + myomectomy & $1(0.99)$ \\
\hline $\begin{array}{l}\text { 2 caesarean section+ ovarian } \\
\text { cystectomy }\end{array}$ & $1(0.99)$ \\
\hline Appendectomy & $2(1.98)$ \\
\hline Ovarian cystectomy & $58(57.4)$ \\
\hline Myomectomy & \\
\hline Nil & \\
\hline
\end{tabular}

Table 2: Comparison of uterine size in weeks and uterine volume (cc).

\begin{tabular}{|lll|}
\hline $\begin{array}{l}\text { Uterus size } \\
\text { (weeks) }\end{array}$ & $\begin{array}{l}\text { Uterus volume }(\text { cc) } \\
\text { Mean } \pm \text { SD }\end{array}$ & Range \\
\hline $\mathbf{8}-\mathbf{9}$ & $101.75 \pm 16.24$ & $70.2-140$ \\
\hline $\mathbf{1 0}-\mathbf{1 2}$ & $210.87 \pm 123.74$ & $72-642$ \\
\hline $\mathbf{1 4}-\mathbf{1 6}$ & $345.24 \pm 113.53$ & $184.2-592$ \\
\hline $\mathbf{1 8}-\mathbf{2 4}$ & $534.47 \pm 132.4$ & $400-802$ \\
\hline
\end{tabular}


In this study, bladder injury was common in the vaginal route $(3.9 \%)$. Out of the 2 cases, 1 was a case of previous lower segment caesarean section (LSCS) and in the other case the volume of the fibroid was high $(582 \mathrm{cc}) .1$ case of bowel injury occurred in the abdominal hysterectomy group and there were none in the vaginal hysterectomy group. Abdominal route showed more incidence of significant blood loss. However all these complications were not statistically significant $(\mathrm{p}=0.076)$ (Table 6).
In this study, majority of women who had undergone vaginal route had no complications $(66 \%)$ compared to women who had undergone abdominal route (34\%). wound infection was seen in 2 cases with abdominal route whereas no case was seen in vaginal hysterectomy. But urinary tract infection (UTI) were more common in vaginal route $3(5.8 \%)$ when compared to abdominal route $2(4 \%)$. Overall, except UTI all other complications are significantly more common with abdominal route $(\mathrm{p}=0.0001)$ (Table 7).

Table 3: Uterine breadth and routes of hysterectomy.

\begin{tabular}{|c|c|c|c|c|}
\hline \multirow{2}{*}{$\begin{array}{l}\text { Uterine } \\
\text { breadth }(\mathrm{cm})\end{array}$} & \multicolumn{2}{|c|}{ Hysterectomies } & \multirow{2}{*}{ Total } & \multirow{2}{*}{ Statistical significance $(\mathbf{P}) *$} \\
\hline & Vaginal & Abdominal & & \\
\hline$<5$ & $21(67.74)$ & $10(32.25)$ & $31(100)$ & \multirow{4}{*}{0.012} \\
\hline $5-10$ & $21(52.5)$ & $19(47.5)$ & $40(100)$ & \\
\hline$>\mathbf{1 0}$ & $9(30)$ & $21(70)$ & $30(100)$ & \\
\hline Total & $51(49.5)$ & $50(50.49)$ & $101(100)$ & \\
\hline
\end{tabular}

Table 4: Comparison of size, volume and weight of uterus in both groups.

\begin{tabular}{|c|c|c|c|}
\hline \multirow{2}{*}{ Characteristic } & \multicolumn{2}{|l|}{ Hysterectomy } & \multirow{2}{*}{ Statistical significance $(\mathbf{P})^{*}$} \\
\hline & Vaginal & Abdominal & \\
\hline Uterus size (weeks) & $8.46 \pm 5.54$ & $13.76 \pm 4.53$ & $0.001 *$ \\
\hline Uterus volume (cc) & $168.09 \pm 139.28$ & $309.12 \pm 182.47$ & $0.001 *$ \\
\hline Uterus weight (g) & $230.92 \pm 223.81$ & $426.39 \pm 396.69$ & $0.003 *$ \\
\hline
\end{tabular}

*Independent student $\mathrm{t}$ test

Table 5: Relationship between uterine volume and routes of hysterectomy, duration of surgery and debulking procedures.

\begin{tabular}{|llllll|}
\hline Uterine volume (cc) & $\mathbf{1 0 0 - 2 0 0}$ & $\mathbf{2 0 1 - 3 0 0}$ & $\mathbf{3 0 1 - 4 0 0}$ & $\mathbf{4 1 0 - 5 0 0}$ & $>\mathbf{5 0 0}$ \\
\hline Total no. of patients $\mathbf{( \% )}$ & $32(31.6)$ & $11(10.89)$ & $17(16.83)$ & $8(7.92)$ & $13(12.87)$ \\
\hline Hysterectomy & & & & & \\
\hline Vaginal route $(\%)$ & $22(68.75)$ & $8(72.7)$ & $5(29.4)$ & $1(12.5)$ & $2(15.3)$ \\
\hline Abdominal route $(\%)$ & $10(31.25)$ & $3(27.27)$ & $12(70.5)$ & $7(87.5)$ & $11(84.6)$ \\
\hline Time of surgery (min) & $45-55$ & $50-65$ & $55-75$ & $60-85$ & $70-85$ \\
\hline Debulking & & 4 & 5 & 1 & 2 \\
\hline
\end{tabular}

Table 6: Comparison of intra-operative complications among abdominal and vaginal hysterectomies.

\begin{tabular}{|c|c|c|c|c|c|}
\hline \multirow{3}{*}{ Intra operative complications } & \multicolumn{4}{|c|}{ Hysterectomy } & \multirow{3}{*}{ Statistical significance $(\mathbf{P}) *$} \\
\hline & \multicolumn{2}{|c|}{ Vaginal } & \multicolumn{2}{|c|}{ Abdominal } & \\
\hline & Count & $\%$ & Count & $\%$ & \\
\hline Nil & 46 & 55.4 & 37 & 44.6 & \multirow{4}{*}{0.076} \\
\hline Bladder injury & 2 & 66.7 & 1 & 33.3 & \\
\hline Significant blood loss & 3 & 21.4 & 11 & 78.6 & \\
\hline Bowel injury & 0 & 0.0 & 1 & 100 & \\
\hline
\end{tabular}

Table 7: Comparison of post-operative complications among abdominal and vaginal hysterectomy.

\begin{tabular}{|c|c|c|c|c|c|}
\hline \multirow{3}{*}{ Post-operative complications } & \multicolumn{4}{|c|}{ Hysterectomy } & \multirow{3}{*}{ Statistical significance $(\mathbf{P}) *$} \\
\hline & \multicolumn{2}{|c|}{ Vaginal } & \multicolumn{2}{|c|}{ Abdominal } & \\
\hline & Count & $\%$ & Count & $\%$ & \\
\hline Nil & 35 & 66 & 18 & 34 & \multirow[t]{2}{*}{0.0001} \\
\hline Febrile morbidity & 5 & 29.4 & 12 & 70.6 & \\
\hline
\end{tabular}

Continued. 


\begin{tabular}{|c|c|c|c|c|c|}
\hline \multirow{3}{*}{ Post-operative complications } & \multicolumn{4}{|c|}{ Hysterectomy } & \multirow{3}{*}{ Statistical significance $(\mathbf{P}) *$} \\
\hline & \multicolumn{2}{|c|}{ Vaginal } & \multicolumn{2}{|c|}{ Abdominal } & \\
\hline & Count & $\%$ & Count & $\%$ & \\
\hline UTI & 3 & 60 & 2 & 40 & \\
\hline Blood transfusion & 8 & 33 & 16 & 66.7 & \\
\hline Wound infection & 0 & 0.0 & 2 & 100 & \\
\hline Total & 51 & 50.5 & 50 & 49.5 & \\
\hline
\end{tabular}

*Chi-square test

\section{DISCUSSION}

Hysterectomy is the most common gynaecological procedure and it is vital to make an evidence based decision to choose an appropriate technique.

In this study maximum number of patients underwent hysterectomy was in the age group 46-50 years (29.7\%). The mean age was 47.55 years. This correlates with other studies - Wong et al, Hwang et al, the mean age was 49 years, and 45 years respectively. ${ }^{6,7}$

In the study conducted by Seth, 3 cases had a uterine volume $>500 \mathrm{cc}$, out of which one case failed vaginally. In present study, out of 13 cases which had a uterine volume $>500 \mathrm{cc}, 2$ cases was done vaginally, of which one case was LAVH. Other 11 cases, were directly taken up for abdominal hysterectomy. In study conducted by Seth, uterine volume up to $400 \mathrm{cc}$ no difficulties were encountered for vaginal hysterectomy. For volume $>400$ cc, debulking was required in all cases as well as greater skill of the surgeon. Vaginal hysterectomy failed in 4 cases with uterine volume 500-700 cc. It was observed that vaginal hysterectomy was done without difficulty up to $300 \mathrm{cc}$ and with debulking and laparascopic assistance up to $400 \mathrm{cc}$. with uterine volume $>500 \mathrm{cc}$, surgeons preferred abdominal route rather than vaginal route. So, it was concluded that up to $300 \mathrm{cc}$ of uterine volume, vaginal route should be preferred route and uterine volume $>300$ cc, expertise and pelvic factor play a major role in determining the route.

When the uterine breadth was less than $5 \mathrm{~cm}$, vaginal hysterectomy was easier to perform. When the breadth of the uterus increases, retrieval of the specimen through the vaginal route might be difficult and might require debulking. Uterine breadth can be used as a reliable tool to predict if the specimen can be removed vaginally without any difficulty or to anticipate the need for any debulking methods during surgery.

In this study, overall uterine weight is more in abdominal route than vaginal route. Similar observation was seen in the study done by Wong et al (Table 8$){ }^{6}$

In this study uterine weight measured post operatively correlated with the uterine volume measured on USG. This can also be compared with other studies done by Kung et al showed a positive correlation between pre operatively measured uterine volume and post-operative uterine weight. ${ }^{6}$

Mean operative time $(54.4 \pm 4.54)$ in minutes and hospital stay $(2.50 \pm 0.69)$ in days was less with vaginal hysterectomy when compared to abdominal hysterectomy which was statistically significant $(\mathrm{p}=0.001)$. This was also similar to other studies done by Chen et al and Mehta et al (Table 9). ${ }^{10,11}$

Table 8: Comparison of mean uterine weight with other studies.

\begin{tabular}{|c|c|c|c|c|c|c|}
\hline \multirow[b]{2}{*}{ Parameters } & \multicolumn{2}{|l|}{ Abdominal } & \multicolumn{2}{|l|}{ Vaginal } & \multicolumn{2}{|l|}{ Overall } \\
\hline & Present study & $\begin{array}{l}\text { Wong et al } \\
\text { study }\end{array}$ & Present study & $\begin{array}{l}\text { Wong et al } \\
\text { study }\end{array}$ & Present study & $\begin{array}{l}\text { Wong et al } \\
\text { study }\end{array}$ \\
\hline $\begin{array}{l}\text { Uterine weight } \\
\text { in mean } \pm S D(g)\end{array}$ & $426.39 \pm 396.69$ & $449 \pm 386.7$ & $230.92 \pm 223.8$ & $164 \pm 109.5$ & $337.4 \pm 342.18$ & $312 \pm 313.8$ \\
\hline$>280 \mathrm{~g}(\%)$ & 58 & 62.3 & 21 & 11.2 & 39 & 38.6 \\
\hline
\end{tabular}

Table 9: Operative time and hospital stay in both groups.

\begin{tabular}{|c|c|c|c|c|c|c|}
\hline \multirow[b]{2}{*}{ Parameters } & \multicolumn{3}{|l|}{ Abdominal } & \multicolumn{3}{|l|}{ Vaginal } \\
\hline & Present study & $\begin{array}{l}\text { Chen et al } \\
\text { study }\end{array}$ & $\begin{array}{l}\text { Mehta et al } \\
\text { study }\end{array}$ & $\begin{array}{l}\text { Present } \\
\text { study }\end{array}$ & $\begin{array}{l}\text { Chen et al } \\
\text { study }\end{array}$ & $\begin{array}{l}\text { Mehta et al } \\
\text { study }\end{array}$ \\
\hline $\begin{array}{l}\text { Mean operative } \\
\text { time (min) }\end{array}$ & $65.2 \pm 10.24$ & $95.6 \pm 15.9$ & $77.6 \pm 12.92$ & $54.4 \pm 4.54$ & $65.2 \pm 10.6$ & $69.8 \pm 14.06$ \\
\hline $\begin{array}{l}\text { Hospital stay } \\
\text { (days) }\end{array}$ & $3.38 \pm 0.73$ & $6.3 \pm 1.5$ & $>4$ & $2.50 \pm 0.69$ & $4.5 \pm 0.5$ & $<4$ \\
\hline
\end{tabular}


In present study post-operative blood transfusion are more with abdominal hysterectomy (32\%) compared to vaginal hysterectomy (15.6\%) and no cases of wound infection is seen with vaginal hysterectomy. Similar outcomes are seen in other studies. Balakrishnan et al and Mehta et al studies also showed post-operative blood transfusion and wound infection are more in abdominal hysterectomy. ${ }^{11,12}$

\section{CONCLUSION}

In this study, found that preoperative uterine volume upto $300 \mathrm{cc}$ vaginal route can be done. Mean operative time, hospital stay and post-operative complications were less with vaginal route. There is an increasing trend towards minimally invasive surgeries, however vaginal hysterectomy is still a preferred route with minimal morbidity.

By comparing the pre-operative uterine volume and the post-operative uterine weight, it is found that uterine volume on USG can be a good predictor in deciding whether hysterectomy via vaginal route is possible or to prefer laparoscopic assistance or abdominal route may be needed.

For all patients undergoing hysterectomy, vaginal hysterectomy is the preferred choice unless it is contraindicated. Hence pre-operative counselling the patient and family members plays a crucial role in reviving this dying art of vaginal hysterectomy in the era of minimally invasive surgery.

\section{ACKNOWLEDGMENTS}

Authors would like to thank all the patients who have participated in the study and for expressing their willingness to be a part of the study. They would sincerely like to thank colleagues Dr. Sivakamini, Dr. Pavani, Dr. Lavanya, Dr. Jaissree and husband Dr. Haneef for their help rendered, also Dr. Balaji who has helped in the statistical analysis in the study.

Funding: No funding sources

Conflict of interest: None declared

Ethical approval: The study was approved by the Institutional Ethics Committee

\section{REFERENCES}

1. Casikar I, Mongelli M, Reid S, Condous G. Estimation of uterine volume: A comparison between Viewpoint and 3D ultrasound estimation in women undergoing laparoscopic hysterectomy. Australas J Ultrasound Med. 2015;18(1):27-32.
2. Kovac SR, Cruikshank SH, Patwari A, O’Meara P. 28 Years of Using Hysterectomy Guidelines to Determine the Feasibility of Vaginal Hysterectomy. Gynecol Obstet (Sunnyvale). 2016;6:375.

3. Sheth SS, Hajari AR, Lulla CP, Kshirsagar D. Sonographic evaluation of uterine volume and its clinical importance. J Obstet Gynaecol Res. 2017;43:185-9.

4. Kung FT, Chang SY. The relationship between ultrasonic volume and actual weight of pathologic uterus. Gynecol Obstet Invest. 1996;42(1):35-8.

5. American College of Obstetricians and Gynecologists. Choosing the route of hysterectomy for benign disease. Committee Opinion No. 701. Obstet Gynecol. 2017:129:155-9.

6. Wong FWS, Lim DCE. Factors influencing the choice of hysterectomy approach for the management of fibroid uterus. Gynecol Minim Invasive Ther. 2013;2:61-4.

7. Hwang JL, Seow KM, Tsai YL, Huang LW, Hsieh BC, Lee C. Comparative study of vaginal, laparoscopically assisted vaginal and abdominal hysterectomies for uterine myoma larger than $6 \mathrm{~cm}$ in diameter or uterus weighing at least $450 \mathrm{~g}$ : a prospective randomized study. Act Obstet Gynecol Scand. 2002;81(12):1132-8.

8. Seth SS, Shah NM. Preoperative sonographic estimation of uterine volume; an aid to determine the route of Hysterectomy. J Gynecolo Surg. 2002;18(1):13-22.

9. Kung FT, Chang SY. The relationship between ultrasonic volume and actual weight of pathologic uterus. Gynecol Obstet Invest. 1996;42(1):35-8.

10. Chen B, Ren DP, Li JX, Li CD. Comparison of vaginal and abdominal hysterectomy: A prospective non-randomized trial. Pak J Med Sci. 2014;30(4):8759.

11. Mehta K, Prakash O, Fatehpuriya DS, Verma L. Comparative study of abdominal hysterectomy and vaginal hysterectomy in non-descent cases a prospective study. Int $\mathbf{J}$ Reprod Contracept Obstet Gynecol. 2017;6:1265-70.

12. Balakrishnan D, Dibyajyoti GA. Comparison Between Non-Descent Vaginal Hysterectomy and Total Abdominal Hysterectomy J Clin Diagn Res. 2016;10(1):11-4.

13. Chandrakar K, Singh N, Charla S. Comparative study on non-descent vaginal hysterectomy verses abdominal hysterectomy for benign uterine conditions. Int J Med Res Rev. 2016;4(11):2071-6.

Cite this article as: Hanifa D, Thakkar NA, Premalatha R. Uterine volume measurement as a determinant in route of hysterectomy. Int J Reprod Contracept Obstet Gynecol 2021;10:4157-62. 